\title{
Genome-Wide Analysis Reveals a RhIA-Dependent Modulation of Flagellar Genes in Pseudomonas Aeruginosa PA01
}

\section{Michele Castro}

Federal University of Rio de Janeiro

Graciela Maria Dias

Federal University of Rio de Janeiro

Tiago Salles

Federal University of Rio de Janeiro

Núbia Cabral

Federal University of Rio de Janeiro

Danielly Mariano

Federal University of Rio de Janeiro

Hadassa Oliveira

Federal University of Rio de Janeiro

Eliana Abdelhay

Instituto Nacional do Câncer

Renata Gomes

Instituto Nacional do Câncer

Bianca Neves ( $\sim$ bcneves@iq.ufrj.br)

Federal University of Rio de Janeiro

\section{Research Article}

Keywords: Pseudomonas aeruginosa, Rhamnolipids, Swarming Motility, Flagella, Transcriptomic Profile

Posted Date: February 8th, 2021

DOI: https://doi.org/10.21203/rs.3.rs-154442/v1

License: (c) (i) This work is licensed under a Creative Commons Attribution 4.0 International License.

Read Full License

Additional Declarations: No competing interests reported. 
Version of Record: A version of this preprint was published at Current Genetics on January 30th, 2022. See the published version at https://doi.org/10.1007/s00294-021-01225-9. 
Genome-wide analysis reveals a RhIA-dependent modulation of flagellar genes in Pseudomonas aeruginosa PAO1

Michele R. Castro, ${ }^{1,2}$ Graciela M. Dias, ${ }^{1}$ Tiago S. Salles, ${ }^{1}$ Núbia M. Cabral, ${ }^{1}$

Danielly C. O. Mariano, ${ }^{1}$ Hadassa L. Oliveira, ${ }^{1}$ Eliana S. F. W. Abdelhay ${ }^{3}$, Renata B. Gomes, ${ }^{3}$ and Bianca C. Neves ${ }^{1 *}$

${ }^{1}$ Department of Biochemistry, Institute of Chemistry, Federal University of Rio de Janeiro (UFRJ), Rio de Janeiro, Brazil

${ }^{2}$ Department of Biology, Federal Institute of Rio de Janeiro (IFRJ), Rio de Janeiro, Brazil

${ }^{3}$ National Cancer Institute (INCA), Rio de Janeiro, Brazil

\section{*Corresponding author}

Bianca C. Neves

Institute of Chemistry, Federal University of Rio de Janeiro (UFRJ)

Avenida Athos da Silveira Ramos, 149, Lab A537

Rio de Janeiro, RJ, 21941-919, Brazil

Telephone: +55 21 3938-7355

FAX: +55 $213938-7266$

e-mail: bcneves@iq.ufrj.br 


\section{Abstract}

Background: Pseudomonas aeruginosa is an opportunistic pathogen and an important model organism for the study of bacterial group behaviors, including cell motility and biofilm formation. Rhamnolipids play a pivotal role on biofilm formation and motility phenotypes in $P$. aeruginosa, possibly acting as wetting agents and mediating chemotactic stimuli. However, no biochemical mechanism or gene regulatory network has been investigated in regard to rhamnolipids' modulation of those group behaviors. Results: Using DNA microarrays, we investigated the transcriptomic profiles in the stationary phase of growth of wild-type $P$. aeruginosa PAO1 and a rhlA-mutant strain, unable to produce rhamnolipids. A total of 134 genes were differentially expressed, comprising different functional categories, indicating a significant physiological difference between the rhamnolipid-producing and non-producing strains. Interestingly, several flagellar genes are repressed in the mutant strain, which directly relates to the non-motile phenotype of the rhlA-minus strain. Swarming motility was restored with the addition of exogenous rhamnolipids obtained from the wild-type strain. Conclusions: Our results show significant evidence that rhamnolipids and/or their precursors, 3-(3hydroxyalkanoyloxy) alkanoic acids, the major biosynthetic products of $r h l A B C$ pathway, seem to modulate gene expression in $P$. aeruginosa. Swarming motility assays support this hypothesis, since the non-motile $r h l A$-mutant strain had its swarming ability restored by the addition of exogenous rhamnolipids.

\section{Keywords}

Pseudomonas aeruginosa, Rhamnolipids, Swarming Motility, Flagella, Transcriptomic Profile 


\section{Background}

Pseudomonas aeruginosa is a ubiquitous bacterium capable of causing opportunistic infection in immunocompromised individuals and is the major pathogen in cystic fibrosis [1]. P. aeruginosa is a model organism for the study of bacterial social behaviour, or 'sociomicrobiology' [2], biofilm development [3] and bacterial motility patterns[4-6]. Multiple factors are involved in bacterial motility and biofilm formation during surface interactions, in which rhamnolipids seem to play a central role [7].

Rhamnolipids are amphipathic molecules composed by a hydrophobic fatty acid moiety and a hydrophilic moiety that may contain one or two L-rhamnose molecules, rendering their surfactant properties [8]. In P. aeruginosa the three most abundant biosurfactants are 3- (3-hydroxyalkanoyloxy) alkanoic acids (HAA), L-rhamnosyl-3hydroxydecanoyl-3-hydroxydecanoate (mono-rhamnolipid) and L-rhamnosyl-Lrhamnosyl-3-hydroxydecanoyl-3-hydroxydecanoate (di-rhamnolipid) [9]. HAAs are synthesized by the enzyme RhlA and is subsequentially converted to mono-rhamnolipid by the enzyme RhlB. Mono-rhamnolipids can then be converted to di-rhamnolipids by the RhlC enzyme. RhlA is therefore a key enzyme in the production of secreted biosurfactants [10] which are a mixture of HAA, mono- and di-rhamnolipids.

Rhamnolipids are typically produced during the stationary phase of growth, as the rhlAB operon is tightly regulated by QS systems [11, 12], and post-transcriptionally regulated by small non-coding RNAs, NrsZ [13] and PhrD [14].

There is evidence that rhamnolipids are necessary for the three-dimensional architecture of biofilm structures and the initial formation of $P$. aeruginosa PAO1 microcolonies during growth in controlled flow systems [3, 7]. They are usually associated to the maintenance of channels between the typical mushroom-like structures and the biofilm dispersion $[3,15]$. Zheng et al., (2017) reported that synthetic analogs of 
rhamnolipids restored structured biofilm formation by a rhlA-mutant strain, in a concentration-dependent manner. In a similar fashion, one of those compounds promoted swarming motility in the rhamnolipid-deficient strain[16].

Surface-associated bacterial motility is also critical for biofilm formation and spatial arrangement, including well-characterized pores and channels [17]. P. aeruginosa has the ability to move through complex motility patterns such as twitching, swimming and swarming [4-6]. Evidence in the literature suggests that rhamnolipids, flagella and type IV pilus are fundamental for motility in P. aeruginosa, particularly for the swarming motility [18-21]. However, the specific molecular mechanisms involved in rhamnolipid modulation of swarming motility and formation of structured biofilms are poorly understood.

In this study, we describe a transcriptome analysis to compare the gene expression profile of $P$. aeruginosa PAO1 and its rhlA-knockout derivative, using Affymetrix GeneChip $^{\mathrm{TM}} P$. aeruginosa genome arrays and real-time qPCR analysis. We tested the hypothesis that rhlA-derived rhamnolipids affect gene expression, under dynamic growth conditions, at the stationary phase of growth. We show that 134 genes were differentially expressed in the rhlA-mutant strain, 91 positively and 43 negatively regulated. Interestingly, the repression of flagellar genes, ultimately involved with swarming motility, was observed. Supporting these findings, the non-motile rhlA-deficient strain had the swarming motility restored when supplemented with rhamnolipids extracted from the wild-type strain. Therefore, we gain mechanistic insight into the role of rhamnolipids in $P$. aeruginosa motility.

\section{Results}

Gene expression profile of a rhlA-deficient strain of P. aeruginosa in stationary phase of growth 
To identify genes possibly regulated in response to secreted biosurfactants in $P$. aeruginosa, we investigated global gene expression in the stationary phase of growth, using a $P$. aeruginosa genome microarray to compare the transcript profiles of a rhlA mutant with its parental strain, PAO1. We identified 134 differentially expressed genes, 91 genes were upregulated and 43 were downregulated (Figure S1; Table S1). Hierarchical clustered heatmaps showed that differentially expressed genes could distinguish between the rhlA-mutant and the control, wild-type strain PAO1 (Table 1; Figure 1). The majority of differentially expressed genes are upregulated in the strain lacking the enzyme RhlA, responsible for production of HAAs and rhamnolipids.

We investigated functional categories of differentially expressed loci that correspond to 134 genes in the previously published annotation of the $P$. aeruginosa genome [1]. As depicted in Figure 2, gene functional classes were obtained through COG database [22], showing an expressive number of genes that encode proteins involved with signaling and basic metabolism mechanisms being positively regulated. Interestingly, we can see that a relevant portion of genes encoding proteins involved in cellular motility are being repressed. On the other hand, genes that encode proteins related to defense mechanisms, which include a type VI secretion system (T6SS) and some virulence factors are being positively regulated (Table 1). Several genes encoding hypothetical proteins with unknown functions have also had their gene expression induced.

Table S1 summarizes the expression data from genome microarray analyses of rhlA-mutant $P$. aeruginosa versus the wild-type strain, PAO1. Among those 134 genes that showed a response to the lack of RhlA of at least 1.5-fold, several were identified as motility-related genes. Interestingly, down-regulation of key flagellar genes was particularly significant, and included class II, III and IV flagellar genes [23, 24]: fleN, fliD, fliT, fliS (class II), flgL (class III), and fliC (class IV). These findings characterize a 
pattern of repression of flagellar genes, which can be directly related to the non-motile phenotype of rhlA-deficient strains, that has been previously described [18-21]. In a similar manner, protein PA3731, annotated as a Phage Shock Protein, for having a predicted secondary structure similar to that of PspA from Escherichia coli, was repressed in the rhlA-mutant strain (-1.57). The PA3731 gene was found to have a positive effect on biofilm formation and swarming motility in P. aeruginosa [25].

On the other hand, upregulation of pilO was observed, a gene that encodes a protein involved in type IV pilus function (T4P) [26], essential to surface adhesion and twitching motility. Other functional gene categories have responded to the absence of RhlA and its biosynthetic products in a similar fashion. Remarkably, hcpl, mapping within an antiprokaryotic type VI secretion system (H1-T6SS) $[27,28]$ of $P$. aeruginosa, showed a positive regulation (Table 1). Of note, expression of several putative tanscriptional regulators was induced: PA0535 (+1.62), PA3458 (+1.86), PA1196 (+2.58) and PA2020 (+2.65).

A pattern of induction of gene expression has been observed in the Mobilome, a category recently included in the COG, that comprises prophages and transposons $[\mathrm{X}]$ : PA0623 (+2.80), PA0620 (+1.96), PA0618 (+2.49), PA0628 (+2.40), PA0616 (+3.30), PA0617 (+1.75), PA0627 (+1.52), PA0619 (+2,36), PA0622 (+1.98), PA0641 (+1.77), PA0625 (+1.57), PA0638 (+1.79) and PA0636 (+3.06). Most bacterial genomes contain phage genomes, known as prophages, maintained in an inactive or lysogenic state. Phage replication in the lysogenic cycle is frequently suppressed and expression of most phage genes is repressed [29]. However, a subset of prophage genes can be expressed as an evolutionary adaptation, conferring a physical conditioning advantage to the bacterial host [30]. 
We have confirmed this approach by measuring gene expression of some selected genes with RT-qPCR, in the wild-type strain and its rhlA-minus derivative strain (see below).

Genes repressed in the rhlA-deficient $P$. aeruginosa strain: confirmation of the microarray analysis by $R T-q P C R$

Four genes of interest that were significantly repressed in the microarray assays were analyzed through RT-qPCR (Figure 3). Key flagellar genes fliC (-1.56), fliT (-2.05), $f l i D(-1.8)$ and $f \lg L(-1.56)$ were selected based on their location at different chromosomal loci, within distinct operons (Figure 3b). Those genes are representatives of three different levels of the hierarchical regulation of flagellar genes (Figure 3b): Class II (fliD and fliT), Class III (flgL), and Class IV (fliC) [24, 31]. In addition, flagellar expression and assembly play a pivotal role on phenotypical traits that also depend on production of HAA and rhamnolipids, especially swarming motility [18-21].

The present assays show that gene repression of the fliC (PA1092), flgL (PA1087), fliD (PA1094) and fliT (PA1096) in the rhlA-deficient strain compared to PAO1 was statistically significant (Figure 3a). The fliC gene showed 91\% of inhibition (Table S3), while genes $f l g L$, fliD, and fliT showed downregulation of 66,60 and $86 \%$, respectively (Table S3). The FlgL, FliD and FliC proteins make up the structure of the flagellum and are present in the extracellular medium [32-34]. FliT is a chaperone that plays an important role in the proper exportation and assembly of proteins that compose the flagellar machinery, including FliD, which is a filament-capping protein $[35,36]$. The single polar flagellum of $P$. aeruginosa is an important virulence and colonization factor of this opportunistic pathogen, having been attributed fundamental roles in the formation of biofilm and bacterial motility [37, 38]. 
Expression of $r h l A$ and $r h l B$ was also assessed by RT-qPCR, since $r h l A$ has been mutated $\left(\Delta r h l A:: \mathrm{Gm}^{\mathrm{R}}\right)[39]$ and $r h l B$ maps within the same operon. In fact, we found that the rhlA-mutation had a polar effect that is shown both in the microarrays (Table 1) and RT-qPCR (Figure 4), as $r h l B$ is substantially repressed.

\section{Swarming motility of a rhlA-deficient $P$. aeruginosa is restored by addition of exogenous Rhamnolipids}

Many studies have demonstrated that $P$. aeruginosa swarming is a complex adaptation process to solid surfaces, in a viscous milieu, that is controlled by a substantial number of cooperating genes, including rhlA [40,41]. To further understand the role of RhlA biosynthetic products on swarming motility, a plate assay was performed with the wild-type $P$. aeruginosa PAO1 and its isogenic rhlA-negative mutant. To determine if the non-motile $r h l A$-mutant strain respond to exogenous rhamnolipids and/or HAAs, the cells were preconditioned with a rhamnolipid extract obtained from the wild-type strain, prior to inoculation onto the swarm plates. Figure 5 shows agar gels with the swarming migration patterns of wild-type $P$. aeruginosa PAO1, a rhlA mutant, which is unable to synthesize rhamnolipids, and the same rhlA mutant after supplementation with an exogenous rhamnolipid extract. The observation of the migration patterns indicates that the rhamnolipid extract modulates the swarming by the RhlA-deficient strain, which responds with the formation of tendrils at the swarm fronts. Therefore, rhamnolipids and/or HAAs may act as inducers of swarming cells. 


\section{Discussion}

P. aeruginosa is among the most common causes of hospital-acquired infections and is often associated with lung infection in cystic fibrosis patients [42]. Some $P$. aeruginosa strains have developed resistance to most antimicrobial agents and are listed by WHO as one of the most critical threats to human health [43]. It produces a wide variety of virulence factors, including specialized protein secretion systems, the ability to form adherent biofilms and typical motility patterns, which account to its adaptability to many different hosts and environments $[44,45]$.

Among its many phenotypical hallmarks, $P$. aeruginosa produces large amounts of rhamnolipids, surface-active amphipathic molecules produced as blends and composed by one or two rhamnose moieties linked to a dimer of $R$-3-hydroxy fatty acids with chain lengths ranging from $\mathrm{C}_{8}$ to $\mathrm{C}_{12}$ [46]. As reviewed by Reis et al. (2011) rhamnolipid biosynthesis in $P$. aeruginosa is directly controlled by quorum sensing, through the transcriptional regulator RhlR, which activates the rhlAB operon when complexed to C4HSL [47]. Most functions attributed to rhamnolipids relate to their well-characterized physicochemical properties. However, there is a lack of comprehensive studies investigating any possible biochemical mechanisms involved in the phenotypes promoted by rhamnolipids in $P$. aeruginosa.

Although the mechanistic role of rhamnolipids in physiology and pathogenesis of P. aeruginosa is not fully understood, there is mounting evidence showing their relation with important virulence traits, such as biofilm formation and flagelar-driven motility [40, 48]. Rhamnolipids have been associated to P. aeruginosa biofilms and play a central role in maintaining the multicellular structures and the dispersion of sessile biofilm cells [3, 
$7,15]$. In a similar manner, the hallmark swarming motility pattern of $P$. aeruginosa is fully dependant on the presence of rhamnolipids [18-21].

DNA microarrays and RT-qPCR have been widely used to analyze the global gene expression of $P$. aeruginosa within its complex adaptative behaviors, including comparative analyses of biofilm versus planktonic cells and the development of a specialized swarming behaviour [40, 49-52]. In the present study, we assessed the genome-wide expression profiles of a wild-type $P$. aeruginosa and its rhamnolipiddeficient derivative, using independent experiments (Figure 1) designed at the stationary phase of growth. Interestingly, the absence of the rhlABC biosynthetic pathway in the mutant strain revealed a broad impact on gene expression profile, including 134 loci in the previously published annotation of the $P$. aeruginosa genome [1], comprising different functional categories (Figure 2). The differential expression of a diverse group of genes indicates that there is a significant physiological difference between the rhamnolipid-producing and non-producing strains. The set of genes was mostly related to motility, prophages, transcription, and translation. Remarkably, a number of genes that encoded signaling proteins were positively regulated, while a relevant portion of genes involved in flagellar motility and chemotaxis were significantly repressed (Table 1, Table S2). Repressed motility-related genes included those encoding type b flagellin $(f l i C)$, two flagellar secretion chaperones (fliS and fliT), a fagellum number regulator protein $(f l e N)$ and a putative chemotaxis transducer (PA2788). On the other hand, the microarray analyses indicated that pilO, related to the biogenesis and functioning of the Type IV pili [26], was upregulated. Some loci encoding two-component systems also had their expression induced, including a putative sensor kinase (PA1180) and NarL (Table S1), which responds to nitrate sensing and modulates motility and virulence [53, 54]. 
Based on the down-regulation profile of flagellar genes observed on the $P$. aeruginosa microarrays and considering their pivotal role on many phenotypes, we selected flagellar genes of different regulatory categories, including class II, III and IV $[23,24]$ for further assessment with RT-qPCR assays. Hence, we further demonstrate a significant repression of flagellar genes $f l i C, f l g L, f l i D$, and fliT in the mutant strain (Figure 3), in the absence of rhamnolipids, the final product of rhlABC biosynthetic pathway.

Previous reports suggest that planktonic and sessile subpopulations of $P$. aeruginosa interact via lasIrhlI quorum sensing signaling, promoting their movement to the top of the adherent microcolonies [37]. This process, apparently mediated by flagella and rhamnolipids, is believed to contribute to the formation of typical mushroom-shaped structures, observed in mature $P$. aeruginosa biofilms [7, 37]. In fact, Pamp \& TolkerNielsen (2007) demonstrated the complete absence of mushroom-like structures in biofilms formed by a rhlA-knockout strain, deficient in the production of rhamnolipids. However, the lack of expression of flagellar genes in the rhlA-mutant strain was not suggested at the time, an evidence that we demonstrate in the present study, for the first time.

In a similar fashion, the ability to produce rhamnolipids has been associated to virulence, using in vitro and in vivo infection models, as a rhamnolipid-deficient $P$. aeruginosa strain was eradicated more rapidly and significantly, when compared to the wild-type parental strain [55]. As far as the swarming motility is concerned, in the light of the present study, this observation could be related to the abrogated motility observed in the rhlA-defective strain (Figure 5) and the downregulation of flagellar genes (Table 1, Figure 3). Supporting this hypothesis, Overhage et al. (2008) provided that under swarming conditions, $P$. aeruginosa PA14 exhibited the upregulation of many virulence- 
related genes, including genes for the Type III Secretion System (T3SS) and its effector proteins [40] required for colonizing host mucosal surfaces.

Expression of type IV fimbriae by $P$. aeruginosa is also associated with its ability to form adherent biofilms onto biotic and abiotic surfaces, twitching and swarming motility. The swarming motility by $P$. aeruginosa is dependent on cell-cell signaling and requires flagella and type IV fimbriae, in addition to the production of rhamnolipids [18, 20, 56]. However, no biochemical mechanism or function has been specifically demonstrated for rhamnolipids in the context of biofilms and motility patterns. It has been proposed that $P$. aeruginosa requires flagella during swarming to overcome adhesive interactions mediated by fimbriae type IV [57]. In fact, swarming motility is abolished in the absence of rhamnolipid-type surfactants, when the rhlA gene is not functional [1821]. In the present study, we show for the first time that the swarming motility can be restored to a rhlA-mutant strain, with addition of exogenous rhamnolipids obtained from the wild-type strain PAO1 (Figure 5).

Adding to the discussion regarding surface interactions, a previous study demonstrated there is an inverse relationship between the production of exopolysaccharides (EPS) and the swarming motility in P. aeruginosa [58]. The knockout of $s a d C$, which codes for diguanylate cyclase SadC, results in a hyperswarmer phenotype, while multicopy expression of this gene promotes a phenotype often associated with overproduction of EPS [58]. Thus, understanding how EPS and motility influence the different $P$. aeruginosa phenotypes can also contribute to the development of strategies against chronic and persistent infections caused by this opportunistic pathogen. Therefore, we also investigated the expression profile of genes related to the EPSs biosynthesis of $P$. aeruginosa PAO1. According to our RT-qPCR results (data not 
shown), we observed an induction of expression of EPS genes (pel and psl components) in the non-motile rhlA-mutant strain, deficient in the production of rhamnolipids, when compared to expression in the wild-type strain. A recently published study also lists the contrast that we see in our analyzes, as null flagellar mutants overexpressed exopolysaccharides Pel and Psl in biofilms of P. aeruginosa, in the laboratory and in biofilms isolated from cystic fibrosis (CF) infection [59].

P. aeruginosa owes its versatility and remarkable adaptative capacity to its large genome, with intricate gene regulatory systems. The $P$. aeruginosa PAO1 genome encodes a wide repertoire of two-component systems (TCSs), with 64 sensor kinases, 72 response regulators and 3 histidine phosphotransfer $(\mathrm{Hpt})$ proteins $[1,60,61]$. These regulatory networks play a central role in several cellular functions and responses, including chemotaxis, surface sensing, and virulence factors. TCSs are known to mediate regulation of flagelar genes, including the GacS network, a complex multikinase network, via SadC [62] or HptB branch [63], which affect the levels of the secondary messenger c-di-GMP. In addition, the Wsp chemosensory system triggers a signal transduction array in response to surface sensing, by controlling the synthesis of c-di-GMP, which promotes the formation of biofilms and decreases the expression of the flagellar genes [64-66]. The main target of c-di-GMP within this pathway is the transcriptional regulator FleQ, which positively regulates the expression of flagellar genes while repressing EPS genes, such as pel. Upon interaction with c-di-GMP, FleQ is inhibited, leading to reduced expression of flagellar genes and upregulation of EPS genes[64, 67]. Therefore, the GacS network and the Wsp signalling pathway represent systems that are compatible to the rhamnolipiddependent modulation of flagellar expression observed in the present study. Interestingly, within the Wsp chemosensory system, flagellar and EPS genes are inversely regulated, a behaviour we have consistently observed in regard to rhamnolipids. FleQ, the master 
regulator of flagelar biogenesis, is the major player in the Wsp system [67]. Whether rhamnolipids would act directly upon any sensory system, or indirectly, through its wetting activity, controlling bacteria's surface sensing, remains to be understood.

We have also identified the positive regulation of $h c p l$, a gene that encodes a component of the type VI protein secretion system (H1-T6SS) [27] and some prophage genes (Table 1, Figure 2). Prophages play an important role in the evolution of bacterial genomes and their pathogenicity [68] and the expression of phage genes has also been shown to cause negative impacts on bacterial motility. A study revealed that flagella are reduced on the surface of cells that overexpress phage genes in strains PAO1 and PA14, in contrast to the observed hyperpiliation by type IV pili [30].

Regarding the data obtained through the DNA microarrays, the present study also revealed that the expression of genes responsive to iron, among which we can highlight PA4221 and PA4220, were negatively regulated in the rhlA-mutant strain (Figure 1 and Table 1). It has been reported that the reduction in iron uptake, in mutants deficient in its acquisition mediated by pyoverdines, may impair the formation of biofilms. However, this deficiency can favor twitching motility in $P$. aeruginosa. Thus, under iron-limiting conditions $P$. aeruginosa presents greater motility and forms unstructured flat biofilms $[69,70]$.

In the last decades, many different approaches are being used for a better understanding of the regulatory mechanisms involved in the formation of biofilm in $P$. aeruginosa. Through a proteomic analysis, a hypothetical protein encoded by the PA3731 gene was identified. The PA3731 gene was related to swarming motility and the synthesis of rhamnolipids. The PA3731-mutant were deficient in biofilm formation compared to the reference strain PAO1 [25]. Corroborating with those data, in our transcriptomic 
analyses, we also observed repression of the PA3731 gene in the rhlA-knockout strain, compared to the wild-type strain.

Taken together, these results show significant evidence that rhamnolipids and/or their HAA precursors, the major biosynthetic products of the rhlABC pathway, seem to modulate gene expression in $P$. aeruginosa. Further investigation is required to understand the biochemical and/or biophysical mechanisms involved in the process.

\section{Conclusions}

The genome-wide transcriptomic analysis revealed that a rhlA-mutant strain, unable to produce rhamnolipids, had a substantially different gene expression profile when compared to the wild-type PAO1. Notably, several key flagellar genes were repressed in the mutant strain, suggesting a possible gene regulation pattern mediated by rhamnolipids and/or their HAA precursors. Swarming motility assays support this hypothesis, since the non-motile rhlA-mutant strain had its swarming ability restored by the addition of exogenous rhamnolipids.

\section{Methods}

\section{Bacterial strains and growth conditions}

P. aeruginosa strains used in the study were stored at $-80^{\circ} \mathrm{C}$ in Lysogeny Broth medium (LB; 10.0 g/L Tryptone, 5.0 g/L Yeast Extract, 5.0 g/L NaCl; Sigma-Aldrich, St. Louis, USA) supplemented with $20 \%$ (v/v) glycerol. The wild-type $P$. aeruginosa strain PAO1 [71] and its $r h l A$-knockout derivative $\left(\Delta r h l A:: \mathrm{Gm}^{\mathrm{R}}\right)$ [39] were kindly provided by Professor Gloria Soberón-Chávez of the Universidad Nacional Autónoma de México (UNAM). 
The strains were grown in $250 \mathrm{~mL}$ erlenmeyer flasks containing $100 \mathrm{~mL}$ of LB medium, until the stationary growth phase (OD600 2.0), with shaking (170 rpm), at $30{ }^{\circ} \mathrm{C}$. An aliquot of the culture was collected for total RNA extraction.

\section{RNA extraction and cDNA synthesis}

Total RNA was obtained from bacterial cultures at the the stationary growth phase with the RNeasy® Protect Bacteria Mini Kit (QIAGEN, Hilden, Germany) according to the manufacturer's recommendations. After total RNA extraction, it was treated with 1.0 U/ $\mu 1$ DNAse I (Invitrogen, Thermo Fisher Scientific, Waltham MA, USA) and stored at $-80{ }^{\circ} \mathrm{C}$ for further molecular analysis. The integrity and quality of the extracted genetic material was evaluated by electrophoresis in $0.8 \%$ agarose gel and staining with ethidium bromide. RNA concentration and purity were determined by NanoDrop® 2000 spectrophotometry (Thermo Fisher Scientific, Waltham MA, USA).

For qPCR analyses, cDNA synthesis was obtained with the High-Capacity cDNA Reverse Transcription Kit (Applied Biosystems, Foster City, USA) according to the manufacturer's instructions.

\section{Analysis of the global gene expression profile through DNA microarray}

GeneChip $^{\mathrm{TM}}$ P. aeruginosa Genome Array (Affymetrix, Thermo Fisher Scientific, Waltham MA, USA) was used to analyze the overall gene expression profile, which contains the annotated PAO1 strain genome containing 5,549 protein coding sequences, 18 tRNA genes, one representative of the ribosomal RNA cluster and 117 genes present in other strains of $P$. aeruginosa. In addition, 199 probe sets corresponding to all intergenic regions exceeding 600 base pairs were included.

According to the manufacturer's recommendations for DNA microarray gene expression analysis in prokaryotes, the SuperScript II Reverse Transcriptase enzyme (Thermo Fisher Scientific, Waltham MA, USA) was synthesized after cDNA 
hybridization of random primers $75 \mathrm{ng} / \mu \mathrm{l}$. Subsequently, RNA was removed with $1 \mathrm{M}$ $\mathrm{NaOH}$ solution and neutralized with $1 \mathrm{HCl}$. The MinElute PCR Purification Kit (QIAGEN, Hilden, Germany) was used for cDNA purification, which was quantified and subjected to fragmentation steps $(1.6 \mu \mathrm{g})$. Then, biotin terminal labeling, hybridization, washing and scanning were performed. The experiments were performed in three biological replicates.

Genes were considered differentially expressed in the rhlA-knockout mutant compared to the wild type strain. Expression differences were assessed using comparative and paired analyzes between desired groups, with fold changes $\leq-1.5$ or $\geq 1.5$. The data obtained were processed from the Transcriptome Analysis Console (TAC) Software, version 4.02 (Affymetrix, Thermo Fisher Scientific, Waltham MA, USA). For this purpose, the Gene Level Differential Expression Analysis approach and the ANOVA test were used, with statistical significance for $\mathrm{p}<0.05$ and FDR (False Discovery Rate) of 5\%. The DIAMOND [72] and PseudoCAP [73] tools were also used to identify proteins. Functional categories were determined using the COG database [22].

\section{Confirmation of differentially expressed genes in the microarray by RT-qPCR}

Differentially expressed genes in the microarrays, fliC, flgL, fliD and fliT, related to flagellar motility, were selected for RT-qPCR quantification of expression. The gene used to normalize the experiments was $16 \mathrm{~S}$ rRNA and the expression values of the wild-type strain (PAO1) were adopted as a basal reference (1.0). RT-qPCR was performed with SYBR Green PCR fluorophore Master Mix (Applied Biosystems, Foster City, USA) and the primers were designed with the aid of the online tool Primer3Plus [74] and the Beacon Designer software [75] (Table S3). RT-qPCR was also performed for genes rhlA and rhlB: primers for the $16 \mathrm{~S}$ rRNA, rhlA and $r h l B$ genes were used with TaqMan probes 
synthesized by Life Technologies (Applied Biosystems, Foster City, USA). The relative quantification analyses of $r h l A$ and $r h l B$ gene expression were performed with the 2(Delta Delta C(T)) method [76]. The RT-qPCR reactions were conducted on a CFX96 Real-Time PCR Detection Systems platform (Bio-Rad Laboratories, Hercules, USA).

\section{Production of rhamnolipids}

Rhamnolipids were obtained as previously described [77]. Briefly, P. aeruginosa PAO1 was initially grown overnight in LB broth, at $28{ }^{\circ} \mathrm{C}$, from $-80{ }^{\circ} \mathrm{C}$ stocks and inoculated into $1 \mathrm{~L}$ flasks containing $300 \mathrm{~mL}$ of pre-production medium $\left(\mathrm{K}_{2} \mathrm{HPO}_{4} 7.0\right.$ $\mathrm{g} / \mathrm{L}, \mathrm{KH}_{2} \mathrm{PO}_{4} 3.0 \mathrm{~g} / \mathrm{L}, \mathrm{NaNO}_{3} 1.0 \mathrm{~g} / \mathrm{L}, \mathrm{MgSO}_{4} .7 \mathrm{H}_{2} \mathrm{O} 0.2 \mathrm{~g} / \mathrm{L}$, Glycerol $30.0 \mathrm{~g} / \mathrm{L}$, Yeast Extract $5.0 \mathrm{~g} / \mathrm{L}$, Bacto-Peptone $5.0 \mathrm{~g} / \mathrm{L}$ ) and incubated at $28^{\circ} \mathrm{C} / 170 \mathrm{rpm}$ on a rotary shaker for $40 \mathrm{~h}$. Bacterial pellets were then harvested by centrifugation at $6,000 \times g$ for $25 \mathrm{~min}$ at $25{ }^{\circ} \mathrm{C}$ and inoculated into $250 \mathrm{~mL}$ flasks containing $125 \mathrm{~mL}$ of optimized mineral salt production (MSP) medium $\left(\mathrm{K}_{2} \mathrm{HPO}_{4} 7.0 \mathrm{~g} / \mathrm{L}, \mathrm{KH}_{2} \mathrm{PO}_{4} 3.0 \mathrm{~g} / \mathrm{L}, \mathrm{NaNO}_{3} 1.4\right.$ $\mathrm{g} / \mathrm{L}, \mathrm{MgSO}_{4} .7 \mathrm{H}_{2} \mathrm{O} 0.2 \mathrm{~g} / \mathrm{L}$, Glycerol $30.0 \mathrm{~g} / \mathrm{L}$ ) [77], to a final concentration of $1.0 \mathrm{~g} / \mathrm{L}$ (dry weight). The production of biosurfactants was conducted for 10 days at $28^{\circ} \mathrm{C}$ and $170 \mathrm{rpm}$.

\section{Extraction and quantification of rhamnolipids}

Culture-free supernatants were obtained by centrifugation at $6,000 \times g$ for $25 \mathrm{~min}$, at 15 ${ }^{\circ} \mathrm{C}$ and acidified with $1 \mathrm{~N} \mathrm{HCl}$ into $\mathrm{pH} 3.5$, following the addition of ethyl acetate at a $1: 3$ ratio. Rhamnolipids were then extracted into the organic phase and dried with a HetoDrywinner rotary evaporator (Heto-Holten, Gydevank, Denmark). The resulting preparation was dissolved in methanol, lyophilized and stored at $-20{ }^{\circ} \mathrm{C}$. Prior to use, a $8.0 \mu \mathrm{g} / \mu \mathrm{l}$ rhamnolipid suspension was prepared in electrolyte water solution $(15 \mathrm{mM}$ 
$\mathrm{NaHCO}_{3}, 10 \mathrm{mM} \mathrm{NaCl}$ ). Quantification of rhamnolipids was performed as previously described [78], through quantification of rhamnose with high performance liquid chromatography (HPLC). Briefly, $100 \mu \mathrm{L}$ of a $10 \mathrm{M}$ sulfuric acid solution were added to $1 \mathrm{~mL}$ of rhamnolipids, in electrolyte solution, and heated at $100{ }^{\circ} \mathrm{C}$ for 4 hours. The hydrolyzed solution was neutralized with $10 \mathrm{M}$ sodium hydroxide, filtered with a 0.22 $\mu \mathrm{m}$ membrane and analyzed with HPLC. The HPLC system used in this study was an Agilent 1260 Infinity (Santa Clara, CA, USA) with a refractive index detector. The analytical column was an Aminex HPX-87H (Bio-Rad Laboratories, Hercules, USA), the mobile phase was $5 \mathrm{mM}$ sulfuric acid, with a flow rate of $0.6 \mathrm{~mL} / \mathrm{min}$ and oven temperature of $45^{\circ} \mathrm{C}$. The procedure was carried out in triplicate and a mass spectrometric conversion factor of 2.5 was applied to convert the concentration of rhamnose into rhamnolipids [78].

\section{Plate Swarming Motility Test}

Swarming assays were performed on plates containing 0.5\% agar in M8 medium, supplemented with $0.2 \%$ Glucose, $0.5 \%$ Tryptone and $1 \mathrm{mM} \mathrm{MgSO}_{4}$ [79]. $2.5 \mu \mathrm{L}$ of the cultures were added to the center of the plate and incubated at $30{ }^{\circ} \mathrm{C}$ for 48 hours. In the case of the rhlA-knockout strain $\left(\Delta r h l A:: \mathrm{Gm}^{\mathrm{R}}\right)$ the culture replicates were conditioned with an aqueous rhamnolipid solution, at a final concentration of $4.0 \mu \mathrm{g} / \mu \mathrm{L}$ immediately before application onto the swarming medium.

\section{Statistical analysis}

The samples were compared for expression levels by the control strain (PAO1) and the knockout strain (rhlA-mutant) using the paired t-test of the Graphpad Prism 4.0 program (GraphPad Software Inc, San Diego, CA, USA). Each sample is representative of 3 biological replicates. The significance level established was 95\% $(\mathrm{p}<0.05)$. 


\section{Declarations}

\section{Ethics approval and consent to participate}

Not applicable.

\section{Consent for publication}

Not applicable.

\section{Availability of data and materials}

The datasets generated during the current study are available in the Gene Expression Omnibus (GEO) repository (https://www.ncbi.nlm.nih.gov/geo/), under the accession number GSE163816.

\section{Competing interests}

The authors declare that there is no potential conflict of interest.

\section{Funding}

This work was funded by Petróleo Brasileiro S.A. (Petrobras), Grant No. 0050.0079375.12.9, awarded to BCN. GMD is recipient of a postdoctoral fellowship from Coordenação de Aperfeiçoamento de Pessoal de Nível Superior (CAPES-PrInt).

\section{Authors' Contributions}

BCN conceived and designed the experiments. MRC, RBG, NMC, TSS, and DCOM performed the experiments. MRC, GMD, TSS, HLO, ESFWA, RBG, and BCN analyzed the data. MRC, GMD, DCOM, HLO, ESFWA, RBG, and BCN contributed to manuscript preparation and editing.

\section{Acknowledgements}

We thank Professor Glória Soberón-Chávez for kindly providing the rhlA-mutant strain, obtained from $P$. aeruginosa $\mathrm{PAO} 1$. 


\section{References}

1. Stover CK, Pham XQ, Erwin AL, Mizoguchi SD, Warrener P, Hickey MJ, et al. Complete genome sequence of Pseudomonas aeruginosa PAO1, an opportunistic pathogen. Nature. 2000;406:959-64.

2. Parsek MR, Greenberg EP. Sociomicrobiology: The connections between quorum sensing and biofilms. Trends in Microbiology. 2005.

3. Davey ME, Davey ME, Caiazza NC, Caiazza NC, Toole GAO, Toole GAO. Rhamnolipid Surfactant Production Affects Bio lm Architecture in. Microbiology. 2003;185:1027-36.

4. Rashid MH, Kornberg A. Inorganic polyphosphate is needed for swimming, swarming, and twitching motilities of Pseudomonas aeruginosa. Proc Natl Acad Sci U S A. 2000;97:4885-90.

5. Kearns DB. A field guide to bacterial swarming motility. Nature Reviews Microbiology. 2010.

6. Kilmury SLN, Burrows LL. The Pseudomonas aeruginosa pilSR two-component system regulates both twitching and swimming motilities. MBio. 2018.

7. Pamp SJ, Tolker-Nielsen T. Multiple roles of biosurfactants in structural biofilm development by Pseudomonas aeruginosa. J Bacteriol. 2007;189:2531-9.

8. Maier RM, Soberón-Chávez G. Pseudomonas aeruginosa rhamnolipids: Biosynthesis and potential applications. Applied Microbiology and Biotechnology. 2000.

9. Déziel E, Lépine F, Milot S, Villemur R. Mass spectrometry monitoring of rhamnolipids from a growing culture of Pseudomonas aeruginosa strain 57RP. Biochim Biophys Acta - Mol Cell Biol Lipids. 2000.

10. Soberón-Chávez G, Lépine F, Déziel E. Production of rhamnolipids by Pseudomonas aeruginosa. Applied Microbiology and Biotechnology. 2005.

11. Schuster M, Greenberg EP. Early activation of quorum sensing in Pseudomonas aeruginosa reveals the architecture of a complex regulon. BMC Genomics. 2007. 12. Dobler L, Vilela LF, Almeida R V., Neves BC. Rhamnolipids in perspective: Gene regulatory pathways, metabolic engineering, production and technological forecasting. New Biotechnology. 2016.

13. Wenner N, Maes A, Cotado-Sampayo M, Lapouge K. NrsZ: A novel, processed, nitrogen-dependent, small non-coding RNA that regulates Pseudomonas aeruginosaPAO1 virulence. Environ Microbiol. 2014;16:1053-68.

14. Malgaonkar A, Nair M. Quorum sensing in Pseudomonas aeruginosa mediated by RhlR is regulated by a small RNA PhrD. Sci Rep. 2019; November 2018:1-11. doi:10.1038/s41598-018-36488-9.

15. Boles BR, Thoendel M, Singh PK. Rhamnolipids mediate detachment of Pseudomonas aeruginosa from biofilms. Mol Microbiol. 2005.

16. Zheng H, Singh N, Shetye GS, Jin Y, Li D, Luk YY. Synthetic analogs of rhamnolipids modulate structured biofilms formed by rhamnolipid-nonproducing mutant of Pseudomonas aeruginosa. Bioorganic Med Chem. 2017;25:1830-8. doi:10.1016/j.bmc.2017.01.042.

17. Ghanbari A, Dehghany J, Schwebs T, Müsken M, Häussler S, Meyer-Hermann M. Inoculation density and nutrient level determine the formation of mushroom-shaped structures in Pseudomonas aeruginosa biofilms. Sci Rep. 2016.

18. Kohler T, Curty LK, Barja F, Van Delden C, Pechere JC. Swarming of Pseudomonas aeruginosa is dependent on cell-to-cell signaling and requires flagella and pili. J Bacteriol. 2000. 
19. Déziel E, Lépine F, Milot S, Villemur R. rhlA is required for the production of a novel biosurfactant promoting swarming motility in Pseudomonas aeruginosa: 3-(3hydroxyalkanoyloxy)alkanoic acids (HAAs), the precursors of rhamnolipids. Microbiology. 2003.

20. Caiazza NC, Shanks RMQ, O'Toole GA. Rhamnolipids modulate swarming motility patterns of Pseudomonas aeruginosa. J Bacteriol. 2005.

21. Tremblay J, Richardson AP, Lépine F, Déziel E. Self-produced extracellular stimuli modulate the Pseudomonas aeruginosa swarming motility behaviour. Environ Microbiol. 2007;9:2622-30.

22. Tatusov RL, Galperin MY, Natale DA, Koonin E V. The COG database: A tool for genome-scale analysis of protein functions and evolution. Nucleic Acids Research. 2000 .

23. Dasgupta N, Arora SK, Ramphal R. The Flagellar System of Pseudomonas aeruginosa. In: Pseudomonas. 2004.

24. Copeland MF, Weibel DB. Bacterial swarming: A model system for studying dynamic self-assembly. Soft Matter. 2009.

25. Macé C, Seyer D, Chemani C, Cosette P, Di-Martino P, Guery B, et al. Identification of biofilm-associated cluster (bac) in Pseudomonas aeruginosa involved in biofilm formation and virulence. PLoS One. 2008.

26. Leighton TL, Buensuceso RNC, Howell PL, Burrows LL. Biogenesis of Pseudomonas aeruginosa type IV pili and regulation of their function. Environmental Microbiology. 2015.

27. Sana TG, Berni B, Bleves S. The T6SSs of Pseudomonas aeruginosa strain PAO1 and their effectors: Beyond bacterial-cell targeting. Frontiers in Cellular and Infection Microbiology. 2016.

28. LaCourse KD, Peterson SB, Kulasekara HD, Radey MC, Kim J, Mougous JD. Conditional toxicity and synergy drive diversity among antibacterial effectors. Nat Microbiol. 2018.

29. Owen S V., Canals R, Wenner N, Hammarlöf DL, Kröger C, Hinton JCD. A window into lysogeny: Revealing temperate phage biology with transcriptomics. Microb Genomics. 2020.

30. Tsao YF, Taylor VL, Kala S, Bondy-Denomy J, Khan AN, Bona D, et al. Phage morons play an important role in Pseudomonas aeruginosa phenotypes. J Bacteriol. 2018.

31. Dasgupta N, Wolfgang MC, Goodman AL, Arora SK, Jyot J, Lory S, et al. A fourtiered transcriptional regulatory circuit controls flagellar biogenesis in Pseudomonas aeruginosa. Mol Microbiol. 2003;50:809-24.

32. Minamino T. Protein export through the bacterial flagellar type III export pathway. Biochim Biophys Acta - Mol Cell Res. 2014;1843:1642-8. doi:10.1016/j.bbamcr.2013.09.005.

33. Altegoer F, Bange G. Undiscovered regions on the molecular landscape of flagellar assembly. Current Opinion in Microbiology. 2015.

34. Diepold A, Armitage JP. Type III secretion systems: The bacterial flagellum and the injectisome. Philosophical Transactions of the Royal Society B: Biological Sciences. 2015.

35. Khanra N, Rossi P, Economou A, Kalodimos CG. Recognition and targeting mechanisms by chaperones in flagellum assembly and operation. Proc Natl Acad Sci U S A. 2016.

36. Xing Q, Shi K, Portaliou A, Rossi P, Economou A, Kalodimos CG. Structures of chaperone-substrate complexes docked onto the export gate in a type III secretion 
system. Nat Commun. 2018;9:1-9. doi:10.1038/s41467-018-04137-4.

37. Barken KB, Pamp SJ, Yang L, Gjermansen M, Bertrand JJ, Klausen M, et al. Roles of type IV pili, flagellum-mediated motility and extracellular DNA in the formation of mature multicellular structures in Pseudomonas aeruginosa biofilms. Environ Microbiol. 2008.

38. Kazmierczak BI, Schniederberend M, Jain R. Cross-regulation of Pseudomonas motility systems: The intimate relationship between flagella, pili and virulence. Current Opinion in Microbiology. 2015.

39. Rahim R, Ochsner UA, Olvera C, Graninger M, Messner P, Lam JS, et al. Cloning and functional characterization of the Pseudomonas aeruginosa rhlC gene that encodes rhamnosyltransferase 2, an enzyme responsible for di-rhamnolipid biosynthesis. Mol Microbiol. 2001;40:708-18.

40. Overhage J, Bains M, Brazas MD, Hancock REW. Swarming of Pseudomonas aeruginosa is a complex adaptation leading to increased production of virulence factors and antibiotic resistance. J Bacteriol. 2008.

41. Xavier JB, Kim W, Foster KR. A molecular mechanism that stabilizes cooperative secretions in Pseudomonas aeruginosa. Mol Microbiol. 2011.

42. Winstanley C, O’Brien S, Brockhurst MA. Pseudomonas aeruginosa Evolutionary Adaptation and Diversification in Cystic Fibrosis Chronic Lung Infections. Trends in Microbiology. 2016.

43. Tacconelli E, Magrini N. Global priority list of antibiotic-resistant bacteria to guide research, discovery, and development of new antibiotics. 2017.

44. Hwang W, Yoon SS. Virulence Characteristics and an Action Mode of Antibiotic

Resistance in Multidrug-Resistant Pseudomonas aeruginosa. Sci Rep. 2019.

45. Malhotra S, Hayes D, Wozniak DJ. Cystic fibrosis and Pseudomonas aeruginosa:

The host-microbe interface. Clinical Microbiology Reviews. 2019.

46. Abdel-Mawgoud AM, Lépine F, Déziel E. Rhamnolipids: Diversity of structures, microbial origins and roles. Applied Microbiology and Biotechnology. 2010.

47. Reis RS, Pereira AG, Neves BC, Freire DMG. Gene regulation of rhamnolipid production in Pseudomonas aeruginosa - A review. Bioresource Technology. 2011.

48. Potvin E, Lehoux DE, Kukavica-Ibrulj I, Richard KL, Sanschagrin F, Lau GW, et al. In vivo functional genomics of Pseudomonas aeruginosa for high-throughput screening of new virulence factors and antibacterial targets. Environ Microbiol. 2003. 49. Whiteley M, Bangera MG, Bumgarner RE, Parsek MR, Teitzel GM, Lory S, et al. Gene expression in Pseudomonas aeruginosa biofilms. Nature. 2001.

50. Lazazzera BA. Lessons from DNA microarray analysis: The gene expression profile of biofilms. Current Opinion in Microbiology. 2005.

51. Shrout JD, Chopp DL, Just CL, Hentzer M, Givskov M, Parsek MR. The impact of quorum sensing and swarming motility on Pseudomonas aeruginosa biofilm formation is nutritionally conditional. Mol Microbiol. 2006.

52. Tremblay J, Déziel E. Gene expression in Pseudomonas aeruginosa swarming motility. BMC Genomics. 2010;11:587. doi:10.1186/1471-2164-11-587.

53. Van Alst NE, Picardo KF, Iglewski BH, Haidaris CG. Nitrate sensing and metabolism modulate motility, biofilm formation, and virulence in Pseudomonas aeruginosa. Infect Immun. 2007.

54. Benkert B, Quäck N, Schreiber K, Jaensch L, Jahn D, Schobert M. Nitrateresponsive NarX-NarL represses arginine-mediated induction of the Pseudomonas aeruginosa arginine fermentation arcDABC operon. Microbiology. 2008.

55. Van Gennip M, Christensen LD, Alhede M, Phipps R, Jensen PØ, Christophersen L, et al. Inactivation of the rhlA gene in Pseudomonas aeruginosa prevents rhamnolipid 
production, disabling the protection against polymorphonuclear leukocytes. APMIS. 2009.

56. O'Toole GA, Kolter R. Flagellar and twitching motility are necessary for Pseudomonas aeruginosa biofilm development. Mol Microbiol. 1998.

57. Murray TS, Kazmierczak BI. Pseudomonas aeruginosa exhibits sliding motility in the absence of type IV pili and flagella. J Bacteriol. 2008.

58. Merritt JH, Brothers KM, Kuchma SL, O'Toole GA. SadC reciprocally influences biofilm formation and swarming motility via modulation of exopolysaccharide production and flagellar function. In: Journal of Bacteriology. 2007.

59. Harrison JJ, Almblad H, Irie Y, Wolter DJ, Eggleston HC, Randall TE, et al. Elevated exopolysaccharide levels in Pseudomonas aeruginosa flagellar mutants have implications for biofilm growth and chronic infections. PLoS Genet. 2020.

60. Rodrigue A, Quentin Y, Lazdunski A, Méjean V, Foglino M. Cell signalling by oligosaccharides. Two-component systems in Pseudomonas aeruginosa: why so many? Trends Microbiol. 2000.

61. Francis VI, Stevenson EC, Porter SL. Two-component systems required for virulence in Pseudomonas aeruginosa. FEMS Microbiology Letters. 2017. 62. Moscoso JA, Jaeger T, Valentini M, Hui K, Jenal U, Filloux A. The diguanylate cyclase SadC is a central player in Gac/Rsm-mediated biofilm formation in Pseudomonas aeruginosa. J Bacteriol. 2014;196:4081-8.

63. Valentini M, Laventie BJ, Moscoso J, Jenal U, Filloux A. The Diguanylate Cyclase HsbD Intersects with the HptB Regulatory Cascade to Control Pseudomonas aeruginosa Biofilm and Motility. PLoS Genet. 2016.

64. Hickman JW, Tifrea DF, Harwood CS. A chemosensory system that regulates biofilm formation through modulation of cyclic diguanylate levels. Proc Natl Acad Sci U S A. 2005.

65. O'Connor JR, Kuwada NJ, Huangyutitham V, Wiggins PA, Harwood CS. Surface sensing and lateral subcellular localization of WspA, the receptor in a chemosensorylike system leading to c-di-GMP production. Mol Microbiol. 2012. 66. Ha D-G, O'Toole GA. c-di-GMP and its Effects on Biofilm Formation and Dispersion: a Pseudomonas aeruginosa Review. Microbiol Spectr. 2015.

67. Hickman JW, Harwood CS. Identification of FleQ from Pseudomonas aeruginosa as a c-di-GMP-responsive transcription factor. Mol Microbiol. 2008.

68. Fortier LC, Sekulovic O. Importance of prophages to evolution and virulence of bacterial pathogens. Virulence. 2013.

69. Patriquin GM, Banin E, Gilmour C, Tuchman R, Greenberg EP, Poole K. Influence of quorum sensing and iron on twitching motility and biofilm formation in Pseudomonas aeruginosa. J Bacteriol. 2008.

70. Glick R, Gilmour C, Tremblay J, Satanower S, Avidan O, Déziel E, et al. Increase in rhamnolipid synthesis under iron-limiting conditions influences surface motility and biofilm formation in Pseudomonas aeruginosa. J Bacteriol. 2010.

71. Holloway BW, Morgan AF. Genome organization in Pseudomonas. Annual review of microbiology. 1986.

72. Buchfink B, Xie C, Huson DH. Fast and sensitive protein alignment using DIAMOND. Nature Methods. 2014.

73. Winsor GL, Lo R, Ho Sui SJ, Ung KSE, Huang S, Cheng D, et al. Pseudomonas aeruginosa Genome Database and PseudoCAP: Facilitating community-based, continually updated, genome annotation. Nucleic Acids Research. 2005.

74. Untergasser A, Nijveen H, Rao X, Bisseling T, Geurts R, Leunissen JAM. Primer3Plus, an enhanced web interface to Primer3. Nucleic Acids Res. 2007. 
75. Thornton B, Basu C. Real-time PCR (qPCR) primer design using free online software. Biochem Mol Biol Educ. 2011;39:145-54.

76. Livak KJ, Schmittgen TD. Analysis of relative gene expression data using real-time quantitative PCR and the 2- $\Delta \Delta \mathrm{CT}$ method. Methods. 2001.

77. Tavares LFD, Silva PM, Junqueira M, Mariano DCO, Nogueira FCS, Domont GB, et al. Characterization of rhamnolipids produced by wild-type and engineered

Burkholderia kururiensis. Appl Microbiol Biotechnol. 2013.

78. Dobler L, De Carvalho BR, De Sousa Alves W, Neves BC, Freire DMG, Almeida RV. Enhanced rhamnolipid production by Pseudomonas aeruginosa overexpressing estA in a simple medium. PLoS One. 2017.

79. Ha DG, Kuchma SL, O'Toole GA. Plate-Based assay for swimming motility in Pseudomonas aeruginosa. Methods Mol Biol. 2014. 


\section{Tables}

Table 1. Summary of expression data from genome microarray analyses of rhlAmutant $P$. aeruginosa versus the wild-type strain PAO1.

\begin{tabular}{|c|c|c|c|}
\hline Protein description & $\begin{array}{l}\text { Gene } \\
\text { name }\end{array}$ & $\begin{array}{c}\text { Gene } \\
\text { number }\end{array}$ & $\begin{array}{c}\text { Fold change } \\
\leq-1.5 \text { or } \geq 1.5 \\
(p-v a l<0.05)\end{array}$ \\
\hline \multicolumn{4}{|l|}{ Carbohydrate transport and metabolism [G] } \\
\hline rhamnosyltransferase chain B & rhlB & PA3478 & $-7.06(2.43 \mathrm{e}-05)$ \\
\hline alcohol dehydrogenase & $\operatorname{adh} A$ & PA5427 & $+3.08(0.0262)$ \\
\hline \multicolumn{4}{|l|}{$\begin{array}{l}\text { Cell cycle control, cell division, chromosome } \\
\text { partitioning [D] }\end{array}$} \\
\hline fagellum number regulator protein FleN & fleN & $\begin{array}{l}\text { PA1454 } \\
{[\mathrm{DN}]}\end{array}$ & $-1.56(0.0212)$ \\
\hline \multicolumn{4}{|l|}{ Cell motility [N] } \\
\hline flagellin type B & fliC & PA1092 & $-1.56(0.0246)$ \\
\hline flagellar protein FliS & fliS & $\begin{array}{l}\text { PA1095 } \\
{[\mathrm{NU}]}\end{array}$ & $-1.63(0.0059)$ \\
\hline fagellum number regulator protein FleN & fleN & $\begin{array}{l}\text { PA1454 } \\
{[\mathrm{DN}]}\end{array}$ & $-1.56(0.0212)$ \\
\hline chemotaxis transducer & & $\begin{array}{l}\text { PA2788 } \\
\text { [NT] }\end{array}$ & $-1.98(0.0024)$ \\
\hline type 4 fimbrial biogenesis protein $\mathrm{PilO}$ & pilO & $\begin{array}{l}\text { PA5042 } \\
\text { [NW] }\end{array}$ & $+1.62(0.0013)$ \\
\hline \multicolumn{4}{|l|}{ Cell wall/membrane/envelope biogenesis [M] } \\
\hline hypothetical protein & & PA0615 & $+1.70(0.0047)$ \\
\hline $\mathrm{N}$-acetylmuramoyl-L-alanine amidase & & PA0807 & $+1.81(0.0090)$ \\
\hline $\begin{array}{l}\text { MexX/AmrA family multidrug efflux RND } \\
\text { transporter periplasmic adaptor subunit }\end{array}$ & & $\begin{array}{l}\text { PA2019 } \\
\text { [MV] }\end{array}$ & $+1.94(0.0001)$ \\
\hline conserved hypothetical protein & & PA4638 & $-1.52(0.0492)$ \\
\hline hypothetical protein & & $\begin{array}{l}\text { PA5232 } \\
\text { [MV] }\end{array}$ & $+1.78(0.0003)$ \\
\hline \multicolumn{4}{|l|}{ Coenzyme transport and metabolism $[\mathrm{H}]$} \\
\hline hypothetical protein & & $\begin{array}{l}\text { PA2501 } \\
\text { [HR] }\end{array}$ & $+1.59(0.0454)$ \\
\hline \multicolumn{4}{|l|}{ Defense mechanisms [V] } \\
\hline $\begin{array}{l}\text { AmrB family multidrug efflux RND transporter } \\
\text { permease subunit }\end{array}$ & & PA2018 & $+1.61(0.0022)$ \\
\hline $\begin{array}{l}\text { MexX/AmrA family multidrug efflux RND } \\
\text { transporter periplasmic adaptor subunit }\end{array}$ & & $\begin{array}{l}\text { PA2019 } \\
\text { [MV] }\end{array}$ & $+1.94(0.0001)$ \\
\hline $\begin{array}{l}\text { putative ATP-binding/permease fusion ABC } \\
\text { transporter }\end{array}$ & & PA5231 & $+1.64(0.0031)$ \\
\hline hypothetical protein & & $\begin{array}{l}\text { PA5232 } \\
\text { [MV] }\end{array}$ & $+1.78(0.0003)$ \\
\hline
\end{tabular}




\begin{tabular}{|c|c|c|}
\hline \multicolumn{3}{|l|}{ Energy production and conversion [C] } \\
\hline nitrite reductase & PA0519 & $-1.93(0.0485)$ \\
\hline phosphate acetyltransferase & PA0835 & $+1.65(0.0491)$ \\
\hline acetate kinase & PA0836 & $+2.28(0.0294)$ \\
\hline \multicolumn{3}{|l|}{ Extracellular structures [W] } \\
\hline type 4 fimbrial biogenesis protein $\mathrm{PilO}$ & $\begin{array}{l}\text { PA5042 } \\
\text { [NW] }\end{array}$ & $+1.62(0.0013)$ \\
\hline \multicolumn{3}{|l|}{ General function prediction only [R] } \\
\hline hypothetical protein & PA1093 & $-1.78(0.0300)$ \\
\hline hypothetical protein & $\begin{array}{l}\text { PA2501 } \\
\text { [HR] }\end{array}$ & $+1.59(0.0454)$ \\
\hline \multicolumn{3}{|l|}{ Inorganic ion transport and metabolism [P] } \\
\hline $\mathrm{K}+/ \mathrm{H}+$ antiporter subunit $\mathrm{F}$ & PA1058 & $+1.51(0.0454)$ \\
\hline ABC transporter ATP-binding protein & PA2329 & $-1.62(0.0486)$ \\
\hline $\mathrm{Fe}(3+)$-pyochelin receptor & PA4221 & $-1.64(0.0440)$ \\
\hline catalase (katA) & PA4236 & $+2.01(0.0200)$ \\
\hline \multicolumn{3}{|l|}{$\begin{array}{l}\text { Intracellular trafficking, secretion, and } \\
\text { vesicular transport [U] }\end{array}$} \\
\hline flagellar protein FliS & $\begin{array}{l}\text { PA1095 } \\
\text { [NU] }\end{array}$ & $-1.63(0.0059)$ \\
\hline \multicolumn{3}{|l|}{ Lipid transport and metabolism [I] } \\
\hline rhamnosyltransferase chain A & PA3479 & $-23.25(5.34 \mathrm{e}-06)$ \\
\hline \multicolumn{3}{|l|}{ Mobilome: prophages, transposons [X] } \\
\hline phage baseplate protein & PA0617 & $+1.75(0.0118)$ \\
\hline bacteriophage protein & PA0618 & $+2.49(0.0033)$ \\
\hline phage tail protein I & PA0619 & $+2.36(0.0088)$ \\
\hline bacteriophage protein & PA0620 & $+1.96(0.0003)$ \\
\hline phage tail sheath family protein & PA0622 & $+1.98(0.0263)$ \\
\hline hypothetical protein & PA0625 & $+1.57(0.0033)$ \\
\hline phage tail protein & PA0627 & $+1.52(0.0034)$ \\
\hline late control protein & PA0628 & $+2.40(0.0006)$ \\
\hline phage tail tape measure protein & PA0636 & $+3.06(0.0043)$ \\
\hline phage minor tail protein $\mathrm{L}$ & PA0638 & $+1.79(0.0082)$ \\
\hline bacteriophage protein & PA0641 & $+1.77(0.0008)$ \\
\hline
\end{tabular}

\begin{tabular}{lcc}
\hline Signal transduction mechanisms $[\mathbf{T}]$ & & \\
\hline sigma-54-dependent Fis family transcriptional & PA1196 & $+2.58(0.032)$ \\
regulator & {$[\mathrm{KT}]$} & \\
\hline chemotaxis transducer & PA2788 & $-1.98(0.0024)$ \\
& {$[\mathrm{NT}]$} & \\
\hline
\end{tabular}

\section{Transcription [K]}




\begin{tabular}{|c|c|c|}
\hline $\begin{array}{l}\text { sigma-54-dependent Fis family transcriptional } \\
\text { regulator }\end{array}$ & $\begin{array}{l}\text { PA1196 } \\
\text { [KT] }\end{array}$ & $+2.58(0.0320)$ \\
\hline transcriptional regulator TetR family & PA2020 & $+2.65(0.0191)$ \\
\hline transcriptional regulator & PA3458 & $+1.86(0.0333)$ \\
\hline \multicolumn{3}{|l|}{$\begin{array}{l}\text { Translation, ribosomal structure and biogenesis } \\
{[\mathrm{J}]}\end{array}$} \\
\hline hypothetical protein & PA1746 & $+1.72(0.0005)$ \\
\hline \multicolumn{3}{|l|}{ Uncharacterized } \\
\hline holin & PA0614 & $+3.30(0.0001)$ \\
\hline hypothetical protein & PA0621 & $+2.03(0.0072)$ \\
\hline lipoprotein & PA0631 & $+1.72(0.0006)$ \\
\hline hypothetical protein & PA0633 & $+2.13(0.0207)$ \\
\hline hypothetical protein & PA0635 & $+2.14(0.0011)$ \\
\hline hypothetical protein & PA0646 & $+1.67(0.0079)$ \\
\hline phage holin family protein partial & PA0909 & $+1.72(0.0005)$ \\
\hline hypothetical protein & PA0911 & $+1.62(0.0056)$ \\
\hline flagellar protein FliT* & PA1096 & $-2.05(0.0112)$ \\
\hline DUF4280 domain-containing protein & PA2375 & $-1.54(0.0135)$ \\
\hline hypothetical protein & PA4139 & $-2.28(0.0364)$ \\
\hline protein FptB & PA4220 & $-1.54(0.0397)$ \\
\hline hypothetical protein & PA4377 & $-2.57(0.0009)$ \\
\hline hypothetical protein & PA4570 & $-1.84(0.0225)$ \\
\hline
\end{tabular}

(*) FliT is a key flagellar chaperone that binds to several flagellar proteins in the cytoplasm, including its cognate filamentcapping protein FliD (Khanra et al., 2016). 


\section{Figure legends}

Figure 1. Differentially expressed genes. Hierarchical clustered heatmaps of the datasets show a total of 53 genes, with a fold-change $\leq-1.5$ or $\geq 1.5$ and p-value $<0.05$ between samples of $P$. aeruginosa PAO1 (PAO1 replicas 1, 2 and 3) and rhlA-mutant ( $r h l A$ replicas 1, 2 and 3). The relative differences in gene expression are proportional to the intensity of the coloration (heatmap), with blue referring to decreased and red to increased expression.

Figure 2. Functional classification of $P$. aeruginosa genes differentially expressed in the microarrays. $r h l A$-knockout mutant compared to wild-type parental strain PAO1, with a fold change $\leq-1.5$ or $\geq 1.5$. The analyses were performed using the COG database.

Figure 3. Expression of flagellar genes fliC, flg L, fliD and fliT in P. aeruginosa PAO1 and $\boldsymbol{r h l A}$-mutant strain. a) The graph represents the quantification of mRNA of genes fliC, flgL, fliD and fliT by RT-qPCR, normalized by the 16S rRNA gene, used as endogenous control. Bars indicate \pm standard error. $\left(^{*}\right)$ indicate significantly different values, $\mathrm{p}<0.05$ with the paired t-test. b) Representation of operon organization (nucleotide positions 1164275-1197833 of the PAO1 chromosome) and hierarchical regulation of flagellar genes: Class III (flgL), Class II (fliD and fliT) and Class IV (fliC). Tested genes are represented in blue, black arrows indicate operons and direction of transcription.

Figure 4. Expression of rhlA and rhlB in P. aeruginosa PAO1 and rhlA-mutant strain. The picture shows the quantification of mRNA of a) rhlA and b) rhlB by RTqPCR, with 16S rRNA gene as endogenous control. Expression values of rhlA-mutant strain are relative to the control (PAO1), normalized as 1.0. Bars indicate \pm standard error. Relative expression was calculated using the comparative Cq method.

Figure 5. Swarming motility assay. a) $P$. aeruginosa PAO1, b) rhlA-knockout mutant and c) rhlA-knockout mutant supplemented with exogenous rhamnolipids. 


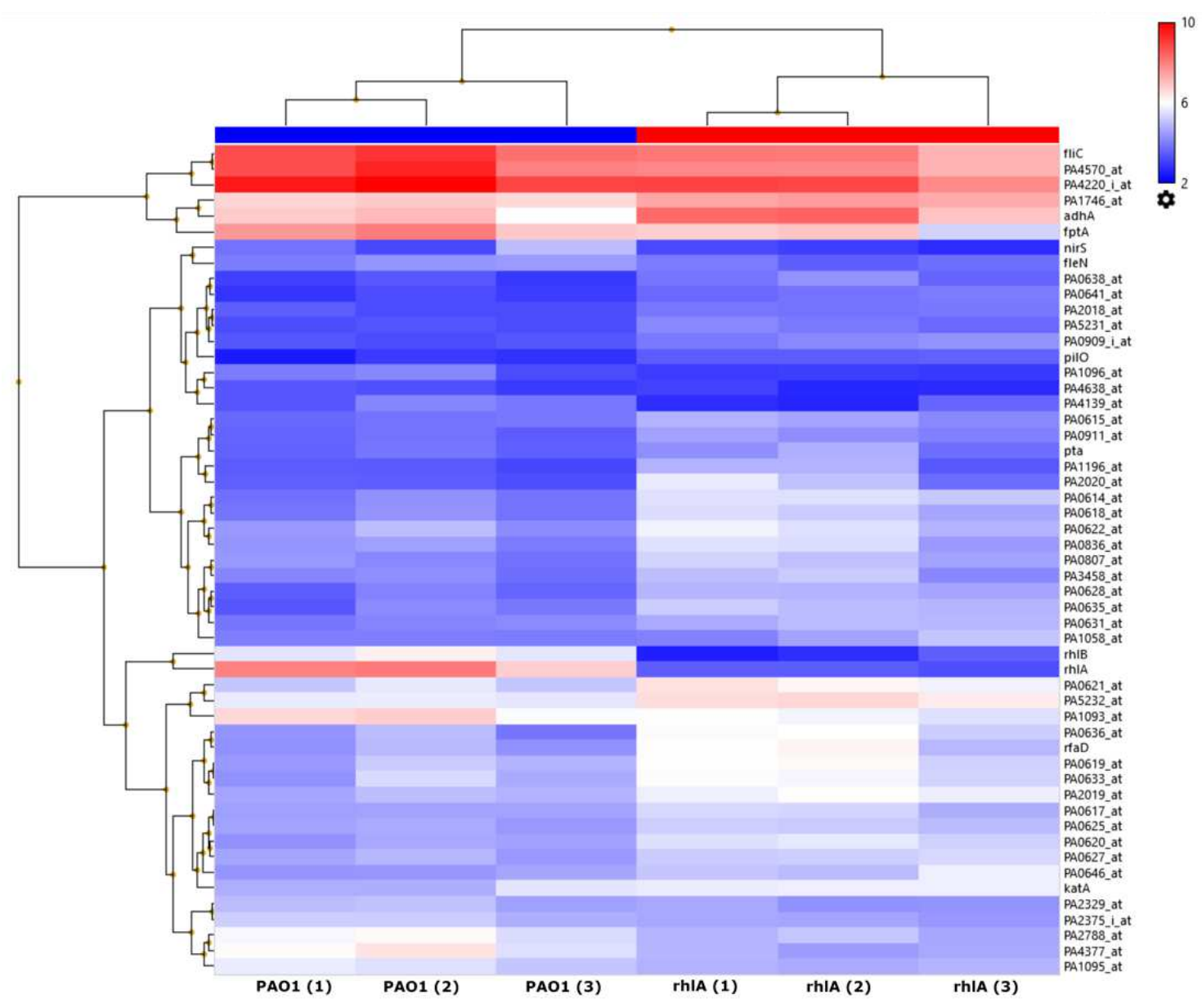

Figure 1 


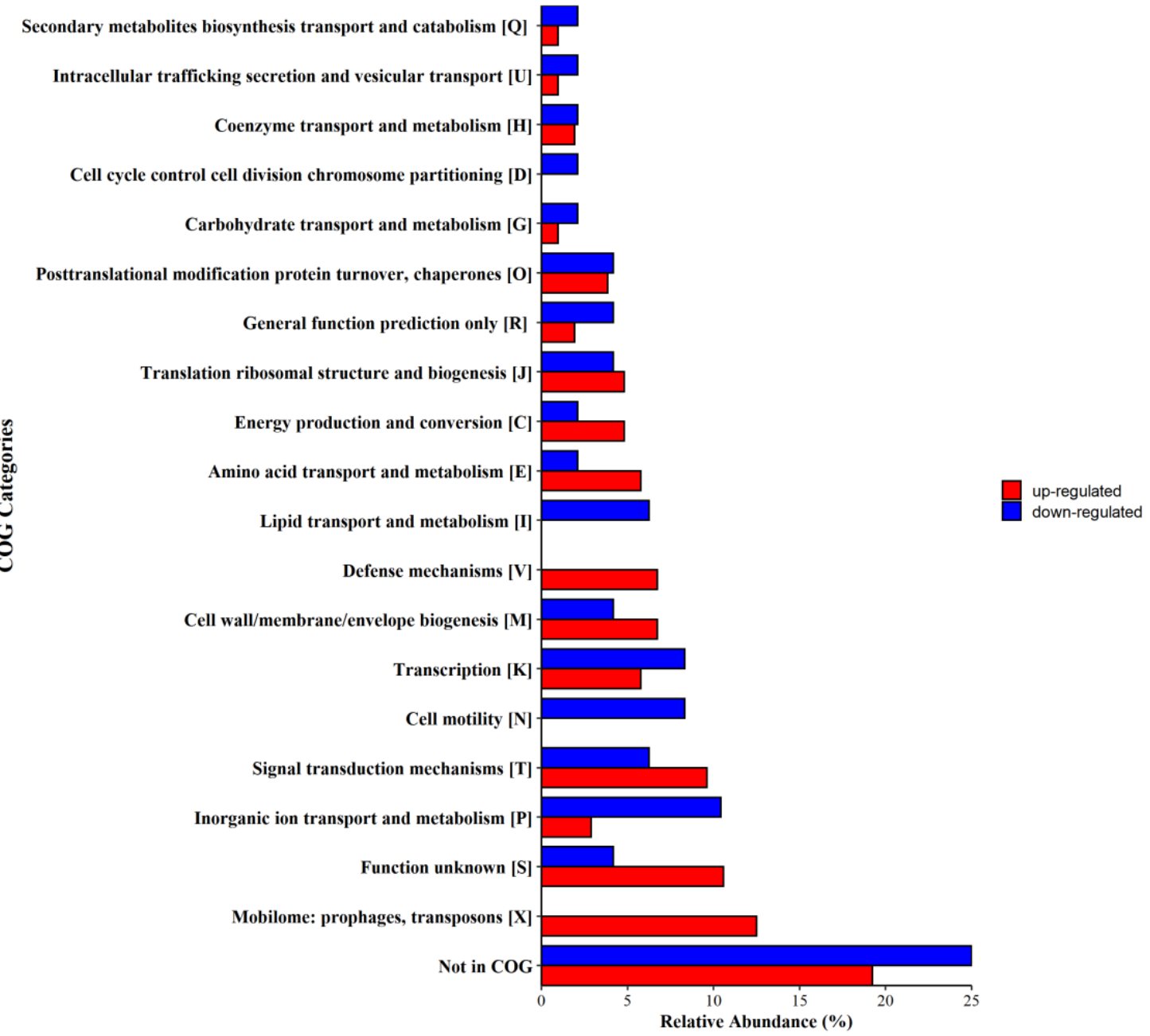

Figure 2 
a)

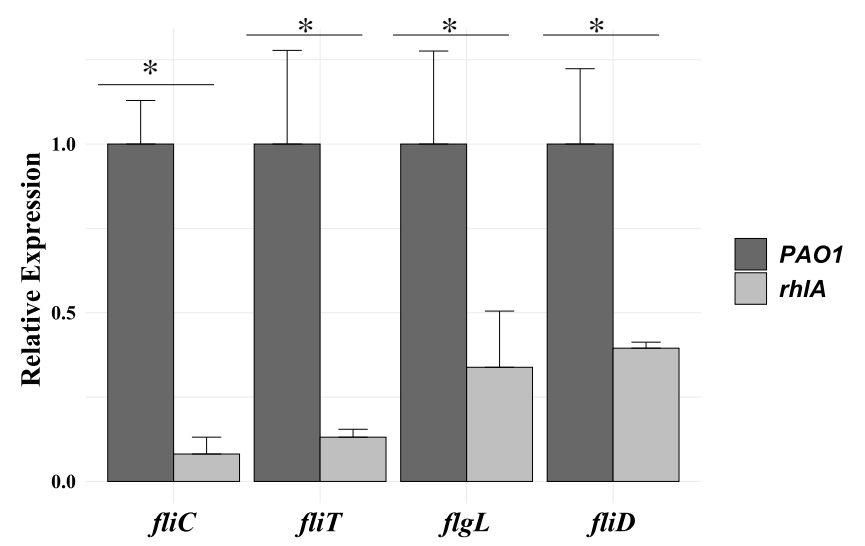

b)
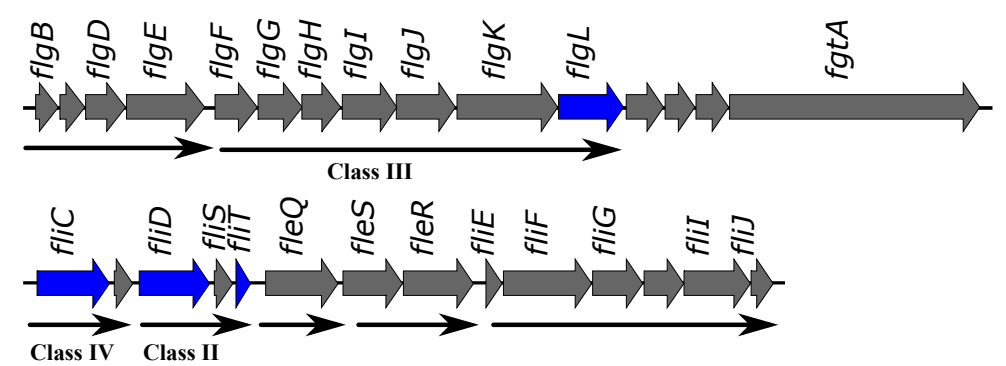

Figure 3 

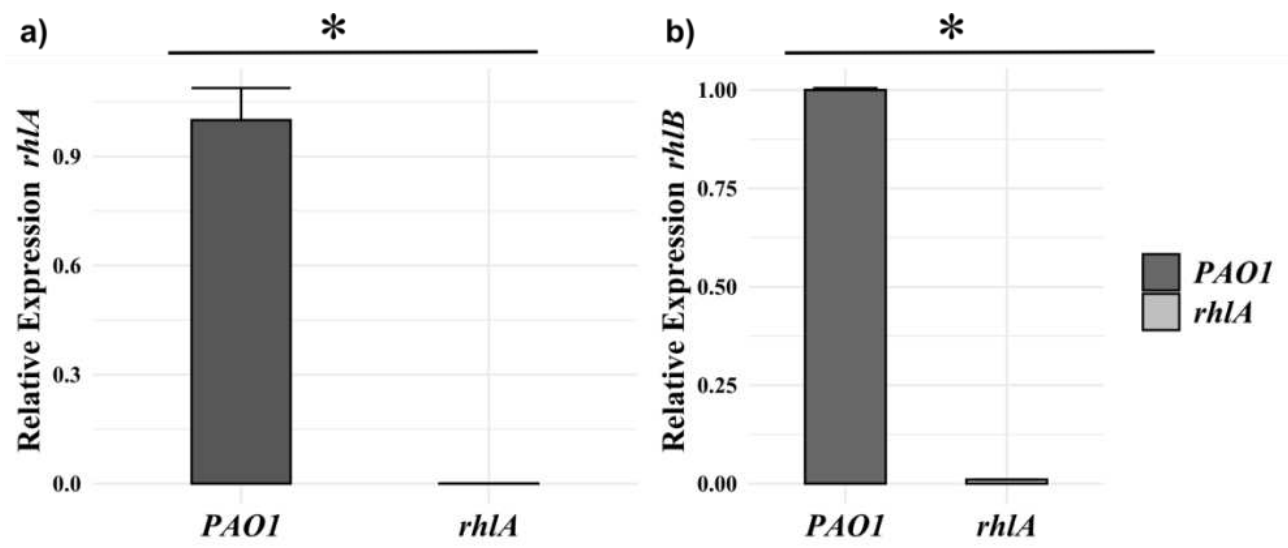

Figure 4 

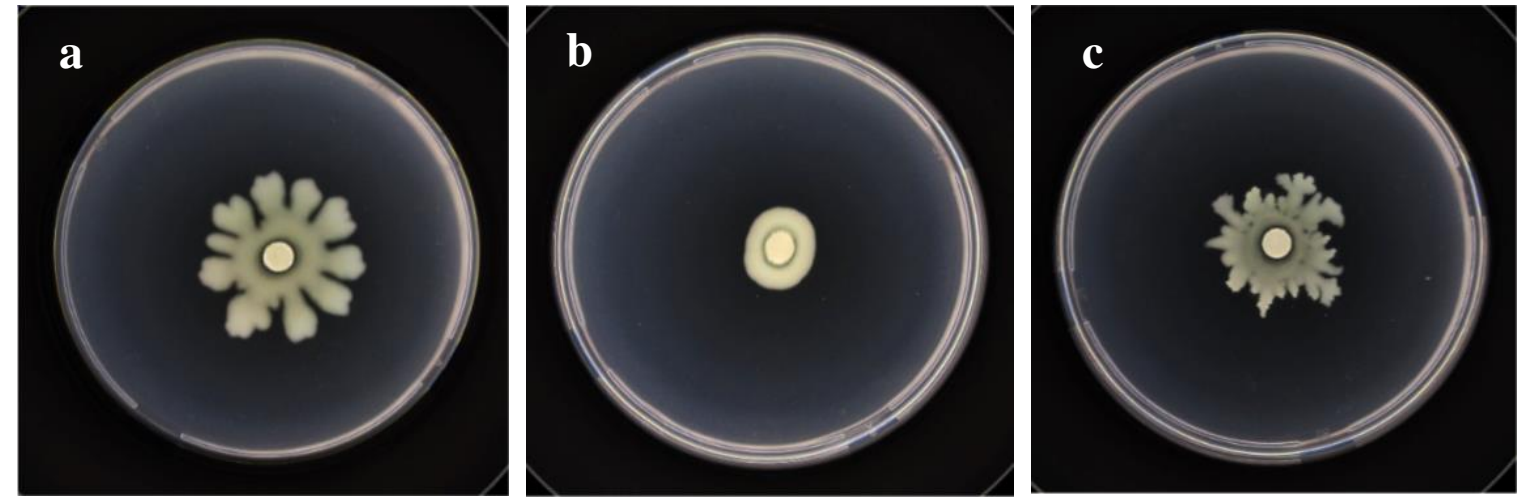

Figure 5 


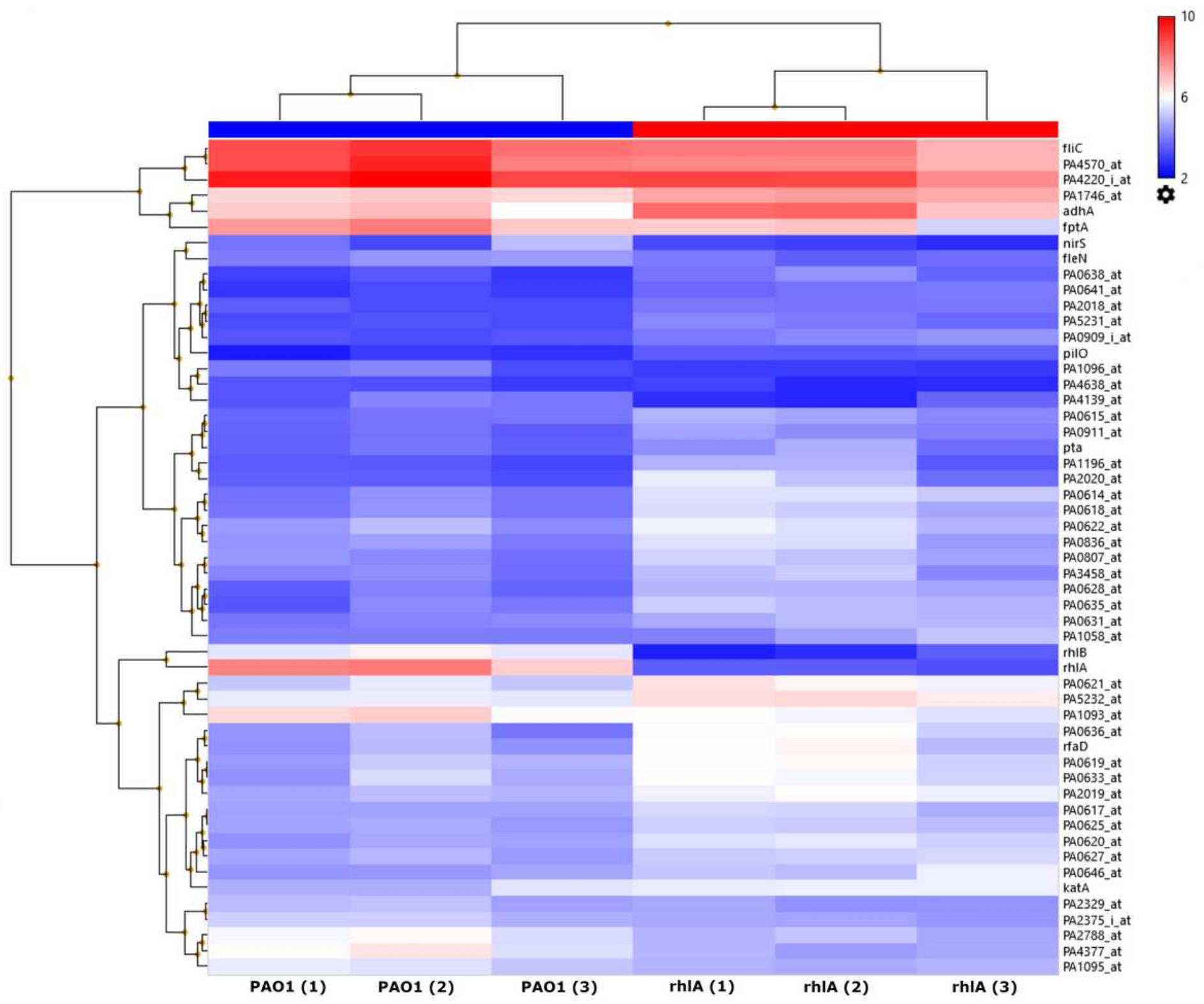

Figure 1

Differentially expressed genes. Hierarchical clustered heatmaps of the datasets show a total of 53 genes, with a fold-change $\leq-1.5$ or $\geq 1.5$ and $p$-value $<0.05$ between samples of P. aeruginosa PA01 (PA01 replicas 1, 2 and 3) and rhIA-mutant (rhIA replicas 1, 2 and 3). The relative differences in gene expression are proportional to the intensity of the coloration (heatmap), with blue referring to decreased and red to increased expression. 
Secondary metabolites biosynthesis transport and catabolism [Q]

Intracellular trafficking secretion and vesicular transport [U]

Coenzyme transport and metabolism $[\mathrm{H}]$

Cell cycle control cell division chromosome partitioning [D]

Carbohydrate transport and metabolism $[G]$

Posttranslational modification protein turnover, chaperones [O]

General function prediction only [R]

Translation ribosomal structure and biogenesis $[\mathrm{J}]$

Energy production and conversion $[\mathrm{C}]$

Amino acid transport and metabolism [E]

Lipid transport and metabolism [I]

Defense mechanisms [V]

Cell wall/membrane/envelope biogenesis [M]

Transcription $[\mathrm{K}]$

Cell motility $[\mathrm{N}]$

Signal transduction mechanisms [T]

Inorganic ion transport and metabolism $[\mathrm{P}]$

Function unknown [S]

Mobilome: prophages, transposons $[\mathrm{X}]$

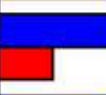

up-regulated

down-regulated

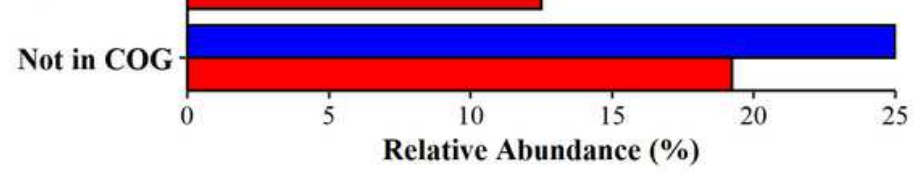

Figure 2

Functional classification of P. aeruginosa genes differentially expressed in the microarrays. rhlA-knockout mutant compared to wild-type parental strain PA01, with a fold change $\leq-1.5$ or $\geq 1.5$. The analyses were performed using the COG database. 
a)

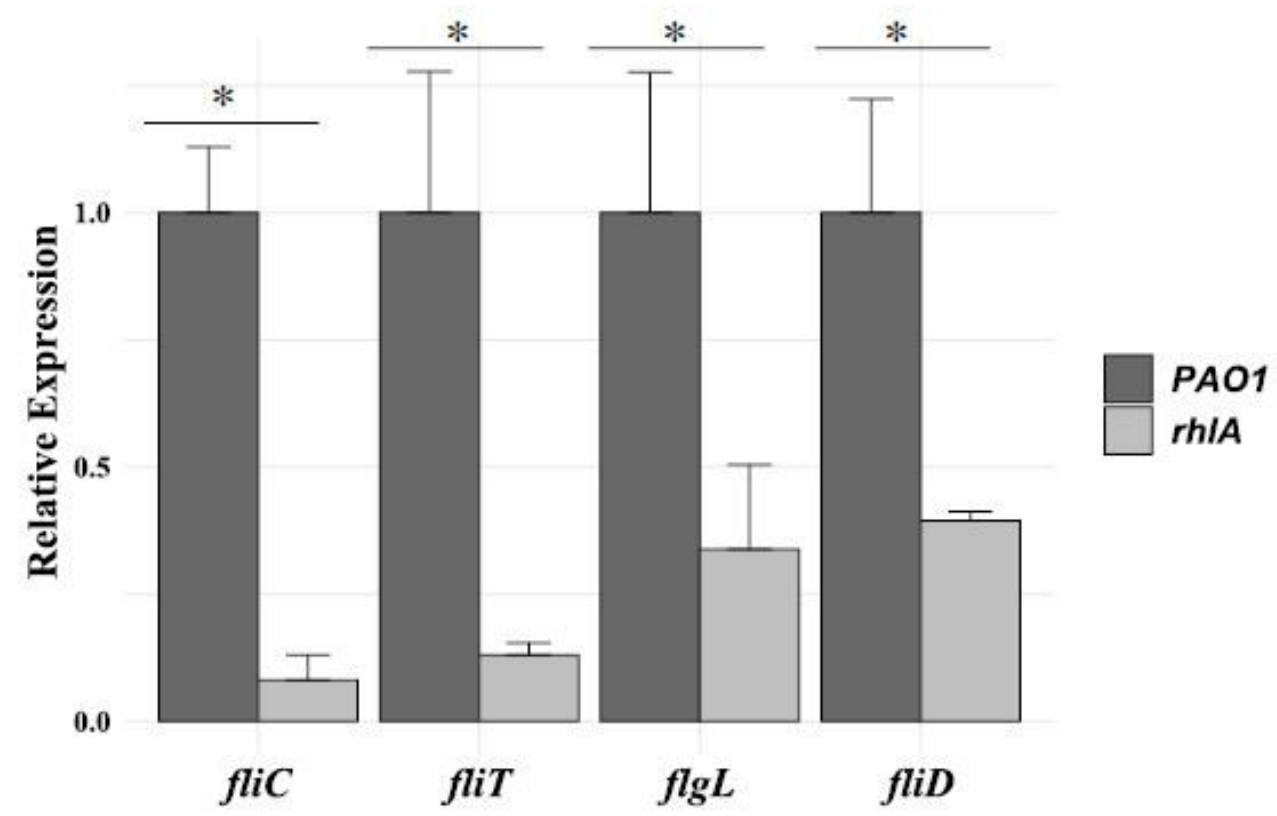

b)
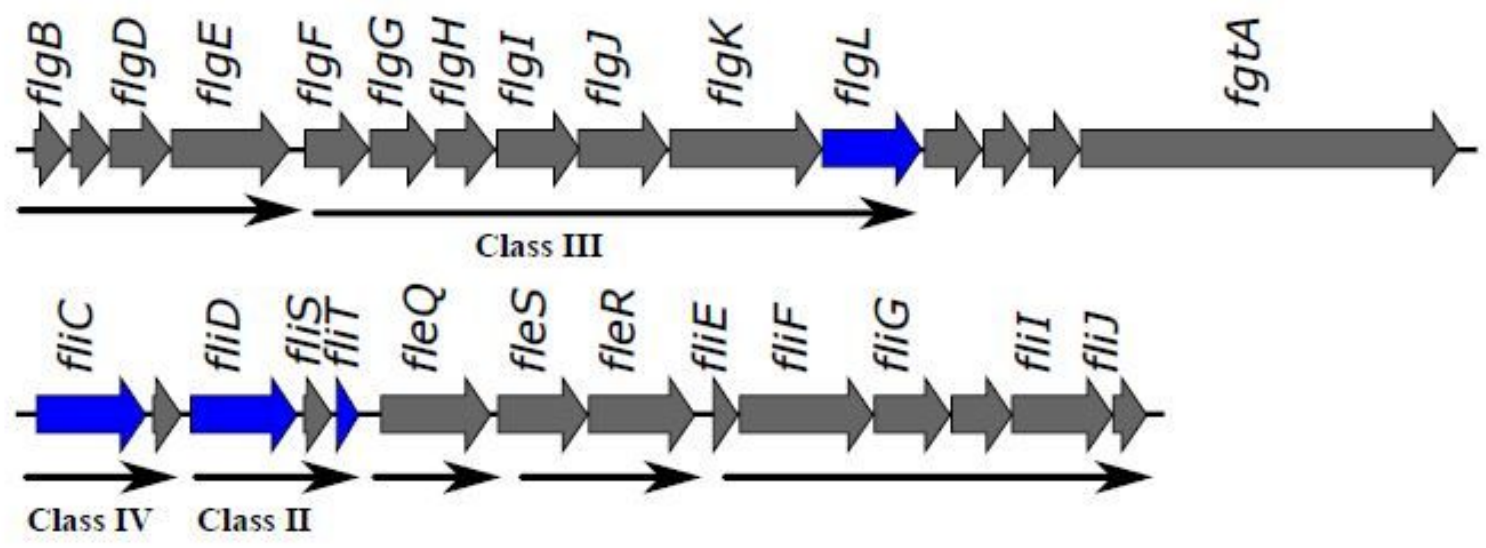

\section{Figure 3}

Expression of flagellar genes fliC, flgL, fliD and fliT in P. aeruginosa PAO1 and rhlA-mutant strain. a) The graph represents the quantification of mRNA of genes fliC, flgL, fliD and fliT by RT-qPCR, normalized by the 16S rRNA gene, used as endogenous control. Bars indicate \pm standard error. (*) indicate significantly different values, $p<0.05$ with the paired t-test. $b$ ) Representation of operon organization (nucleotide positions 1164275-1197833 of the PAO1 chromosome) and hierarchical regulation of flagellar genes: Class III (flgL), Class II (fliD and fliT) and Class IV (fliC). Tested genes are represented in blue, black arrows indicate operons and direction of transcription. 


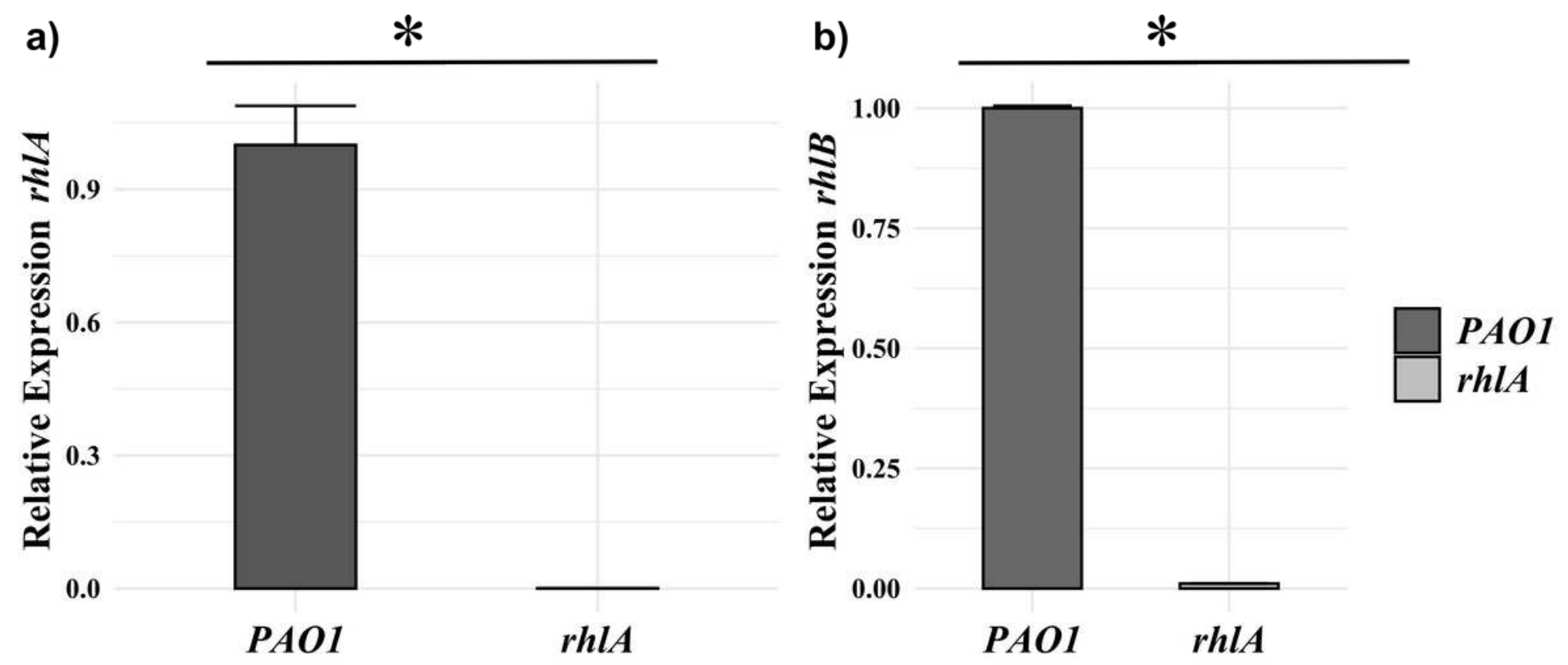

Figure 4

Expression of rhIA and rhIB in P. aeruginosa PAO1 and rhIA-mutant strain. The picture shows the quantification of mRNA of $a$ ) rhlA and $b$ ) rhlB by RT-qPCR, with $16 \mathrm{~S}$ rRNA gene as endogenous control. Expression values of rhIA-mutant strain are relative to the control (PAO1), normalized as 1.0. Bars indicate \pm standard error. Relative expression was calculated using the comparative $\mathrm{Cq}$ method.
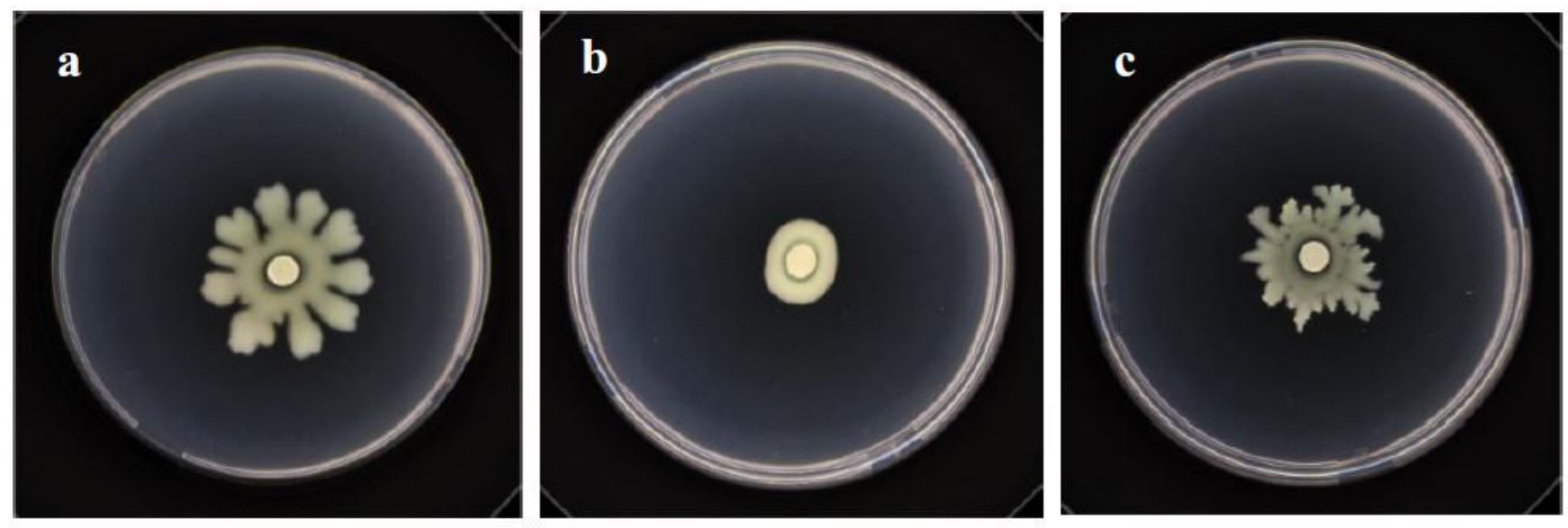

Figure 5

Swarming motility assay. a) P. aeruginosa PAO1, b) rhlA-knockout mutant and c) rhlA-knockout mutant supplemented with exogenous rhamnolipids.

\section{Supplementary Files}


This is a list of supplementary files associated with this preprint. Click to download.

- Castroetal2021SupplementaryFiguresandTables.pdf 